\title{
Socioeconomic Deprivation and Dropout from Contemporary Psychological Intervention for Common Mental Disorders: A Systematic Review
}

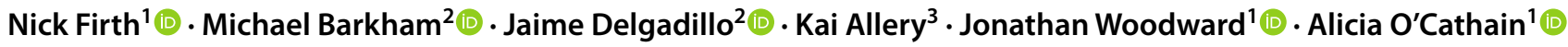

Accepted: 14 November 2021 / Published online: 27 November 2021

(c) The Author(s) 2021

\begin{abstract}
Dropout during psychological intervention is a significant problem. Previous evidence for associations with socioeconomic deprivation is mixed. This study aimed to review the evidence for associations between deprivation and dropout from contemporary adult psychological interventions for common mental disorders (CMDs). Systematic review, narrative synthesis and random effects meta-analysis of peer-reviewed English language journal articles published June 2010-June 2020 was conducted. Data sources included medline, PsycInfo, databases indexed by web of science, ProQuest social science database and sociology collection, and the Cochrane Library, supplemented by forward and backward citation searching. Five studies were eligible for inclusion (mean $N=170,68 \%$ female, $60 \%$ White Caucasian, $32 \%$ dropout rate, predominantly cognitive behaviour therapy/cognitive processing therapy). Narrative synthesis indicated an overall non-significant effect of deprivation on dropout. Meta-analytic significance of controlled $(k=3)$ and uncontrolled $(k=4)$ effects depended on the measure of deprivation included for those studies using more than one measure (controlled OR 1.21-1.32, $\mathrm{p}=0.019-0.172$, uncontrolled OR $1.28-1.76, p=0.024-0.423$ ). The low number of included studies meant sub-group comparisons were limited, despite some tentative indications of potential differential effects. A comparator set of excluded studies showed similar uncertainty. There was limited evidence that did not overall suggest a clear significant effect of deprivation on dropout from contemporary individual CMD interventions. However, more contemporary research is needed, as effects may vary according to clinical and methodological factors, and for dropout versus non-initiation.
\end{abstract}

Keywords Dropout $\cdot$ Deprivation $\cdot$ Socioeconomic $\cdot$ Common mental disorders $\cdot$ Review $\cdot$ Meta-analysis

\section{Introduction}

There is a consistent, well-documented evidence base linking socioeconomic deprivation with a broad range of problems and inequalities (Cookson et al., 2018) across social, physical, and mental health domains (Delgadillo et al., 2016; Eibner et al., 2004; Kuruvilla \& Jacob, 2007; O'Donoghue et al., 2016).

Nick Firth

nick.firth@gmail.com

1 School of Health and Related Research, University of Sheffield, Sheffield S10 2TN, UK

2 Clinical and Applied Psychology Unit, University of Sheffield, Sheffield S10 2TN, UK

3 Medical School, University of Sheffield, Sheffield S10 2TN, UK
Socioeconomic deprivation typically refers to a lack of social and/or economic resources important to living quality (Poverty \& Social Exclusion UK, 2016; Townsend, 1979, 1987). Socioeconomic status, arguably a subtype of deprivation, has most typically been measured by a combination of income, education, and occupation, either on an individual or household level (American Psychological Association, 2007). However, socioeconomic deprivation may also act at other levels such as a person's neighbourhood, and may be measured using metrics such as crime, housing, local services, living environment, and health in addition to those described above (Ministry of Housing, Communities \& Local Government, 2019).

In addition to evidence linking deprivation with greater prevalence of common mental disorders (CMDs) and associated referrals (Delgadillo et al., 2018; Fryers et al., 2003; O'Donoghue et al., 2016), inequalities in the receipt of mental health care have also been found. People living in areas 
of greater deprivation may be less likely to receive psychological intervention (for example via reduced availability or uptake) (Berzins et al., 2018; Delgadillo et al., 2016, 2018; Grant et al., 2012), and the intervention they receive may be less effective on average (Finegan et al., 2018, 2020). This is consistent with the concept of the inverse care law (Hart, 1971), such that the availability of good health care is inversely proportional to the need of the population.

In recent years, efforts have focused on improving access to treatment and reducing care inequalities for people with CMDs, such as the national improving access to psychological therapies (IAPT) programme in England (Clark et al., 2018; NHS Digital, 2020; The National Collaborating Centre for Mental Health, 2019). Despite this, associations between intervention outcomes and deprivation continues to be demonstrated-all significant effects in Finegan et al.'s (2018) recent meta-analysis were published in the last ten years.

This suggests potential ongoing inequalities throughout CMD care pathways that may be limiting clinical effectiveness. Unilateral discontinuation of treatment (also known as treatment dropout) is one factor known to be associated with reduced clinical effectiveness (Barrett et al., 2008; Cahill et al., 2003; Zieve et al., 2019). The success of costly initiatives to directly improve treatment effectiveness (for example, targeted at patients experiencing deprivation) may be limited if such patients do not remain in treatment long enough to experience them. In contrast, understanding dropout could not only improve theoretical models, but also provide a specific "upstream" focus for interventions to enable patients to find more benefit from treatment.

Dropout can also impact clinically and financially on treatment delivery at an organisational level, for example via increased waiting times, detrimental outcomes for other patients, waste of financial and human resources, staff morale/turnover, and negative community perception (Barrett et al., 2008; Klein et al., 2003; Moore et al., 2001). Rates of dropout from psychological treatment are typically estimated at 20-35\% (Cooper \& Conklin, 2015; Roos \& Werbart, 2013; Swift \& Greenberg, 2012).

Previous reviews and meta-analyses examining the association between deprivation and dropout from psychological therapy have indicated certain significant associations between deprivation and dropout (Baekeland \& Lundwall, 1975; Swift \& Greenberg, 2012; Wierzbicki \& Pekarik, 1993). However, early reviews used non-systematic search strategies. They have typically focused on a broad range of predictors, preventing a detailed critical review of socioeconomic deprivation. They have typically included only individual-level socioeconomic variables (excluding e.g., neighbourhood level predictors; Finegan et al., 2020; O'Donoghue et al., 2016; Richardson et al., 2015). They have focused on mental health conditions in general, making conclusions specifically about CMDs difficult, particularly given evidence of differential dropout rates for people with different diagnoses (Swift \& Greenberg, 2012). They have also tended to focus solely on traditional psychotherapy, often using very narrow and limited search terms and therefore potentially excluding relevant studies of psychological intervention.

Furthermore, in recent years the provision of psychological intervention has continued to evolve and change, including increased adoption of stepped care delivery systems, a focus on improving access to intervention, and increasing utilisation of telephone and computer-based interventions, in addition to peripheral technology such as text message communication/reminders (Davison, 2000; Department of Health, 2008, 2011). These approaches may reduce barriers to treatment completion for certain groups-for example, by reducing transport costs, or allowing parents who do not have access to alternative childcare to stay at home with younger children. Conversely, they may bring additional challenges - for example, staying at home may reinforce social isolation, whilst computer interventions may rely more on patients' digital/literacy skills. As such, there is a need for an update of the evidence on deprivation and dropout that reflects the contemporary psychological intervention context.

Finally, this review focuses specifically on dropout once treatment has begun, as distinct from treatment non-initiation. In addition to theoretical arguments for this distinction (e.g., Garfield, 1989), empirical evidence suggests that factors predicting dropout in-treatment may differ from those predicting non-initiation (Kehle-Forbes et al., 2016; Kline et al., 2020; Miller et al., 2019). Kline et al. (2020) suggest that nuance and specificity are likely to be lost if non-initiation and dropout during treatment are not considered as separate heterogeneous types of discontinuation.

\section{Aims}

This review aimed to assess the evidence for associations between socioeconomic deprivation and dropout from contemporary psychological interventions for adults with common mental disorders, by systematically reviewing evidence from peer-reviewed published journal articles. The review question was: To what extent (and in which contexts) is socioeconomic deprivation associated with dropout from contemporary psychological intervention?

The review aimed to focus in particular on evidence regarding indicators of socioeconomic deprivation at the patient level versus neighbourhood level, as well as the impact in different intervention delivery modalities (e.g., face-to-face, telephone, computer-based). The review aimed to minimise heterogeneity risked by the often broad and unfocused inclusion criteria used in previous reviews, by using a refined and targeted search strategy to focus on a 
specific phenomenon (contemporary in-treatment dropout) in a specific population (people experiencing CMDs).

\section{Methods}

Details of this review including the protocol were pre-registered on the PROSPERO International prospective register of systematic reviews (registration number 187034; Firth et al., 2020).

\section{Study Eligibility}

A PICO(SS) framework is presented in Table 1 to summarise the population, intervention, comparator, outcomes, setting, and study design inclusion criteria. The review focused on individually delivered psychological interventions. This decision was made in part to improve homogeneity-in particular, dropout from group and couple treatments may be influenced by other treatment attenders (Firth et al., 2019). Psychological interventions were allowed to be supplemented by other interventions (e.g., pharmacological), as long as the psychological intervention was the primary component of treatment, acknowledging CMD treatment guidelines (National Institute for Health and Care Excellence, 2009, 2011b).

Interventions were required to focus primarily on one or more CMDs. CMDs were first described as "disorders which are commonly encountered in community settings, and whose occurrence signals a breakdown in normal functioning" (Goldberg \& Huxley, 1992, pp. 7-8). Despite challenges and variation in classification (Goldberg \& Huxley, 1992), for this review, CMDs were considered to include: depressive disorders (excluding bipolar disorder), anxiety disorders (including panic and phobic disorders, obsessive-compulsive disorder and body dysmorphic disorder), and post-traumatic stress disorder (PTSD), in line with UK national guidance (National Institute for Health and Care Excellence, 2011a). Examples of exclusions include alcohol and substance use disorders, psychosis and schizophrenia.

Studies were required to include a measure of socioeconomic deprivation as a comparator. Socioeconomic deprivation is defined in this review as the extent of relative disadvantage or lack of resources that contribute to standards of living (e.g., social and economic/material resources) (Bartley \& Blane, 1994; Poverty \& Social Exclusion UK, 2016; Townsend, 1979, 1987).

The outcome measure for this review was dropout from the psychological intervention. Dropout was defined as occurring when a patient who has begun intervention (i.e. attended at least one session) then ends treatment before reaching "mutual agreement that therapy has been completed" (Garfield, 1989). This excluded studies defining dropout as including patients who did not attend any sessions-consistent with Garfield (1989) and empirical literature (Kehle-Forbes et al., 2016; Kline et al., 2020; Miller et al., 2019), this review considers those patients as rejecting or failing to initiate treatment, rather than dropping out.

Common operationalisations of dropout include those based on treatment duration, therapist judgement, and/or termination by failure (discharge due to failing to attend). Duration-based definitions have been widely challenged and it has been suggested that they be treated with caution (Brandt, 1965; Fiester et al., 1974; Pekarik, 1985; Wierzbicki \& Pekarik, 1993). Duration-based measures were only included where there was a consistent agreed treatment duration (e.g., the intervention was pre-specified as being 8 sessions but the patient only attended up to session 5). We believe that to do otherwise risks misrepresenting mutually agreed briefer interventions. Termination by failure is a relatively conservative approach, and therapist judgement has been recommended over other approaches (Wierzbicki \&

Table 1 PICOSS framework

\begin{tabular}{|c|c|c|}
\hline & Eligibility criteria & Exclusions \\
\hline Population & $\begin{array}{l}\text { Adults aged } 18 \text { or over who received an individually-delivered } \\
\text { psychological intervention for a common mental disorder }\end{array}$ & People aged 17 or under \\
\hline Intervention & $\begin{array}{l}\text { Individually delivered outpatient psychological intervention } \\
\text { designed primarily to treat at least one common mental disor- } \\
\text { der, using any modality (e.g., 1:1 face-to-face, telephone, or } \\
\text { computerized interventions) }\end{array}$ & $\begin{array}{l}\text { Group or couples interventions, non-psychological interven- } \\
\text { tions, interventions not focused on treating a common } \\
\text { mental disorder }\end{array}$ \\
\hline Comparator & $\begin{array}{l}\text { Within-group comparison between patients experiencing dif- } \\
\text { ferent extents of socioeconomic deprivation, as assessed by } \\
\text { relevant measures of socioeconomic deprivation }\end{array}$ & \\
\hline Outcomes & Measures of dropout from intervention & \\
\hline Setting & $\begin{array}{l}\text { Any outpatient setting delivering psychological interventions, } \\
\text { worldwide }\end{array}$ & Inpatient settings, penal settings, etc \\
\hline Study & $\begin{array}{l}\text { Peer-reviewed and published empirical quantitative studies } \\
\text { reported in English between June } 2010 \text { and June } 2020\end{array}$ & Qualitative studies, theoretical papers, etc \\
\hline
\end{tabular}


Pekarik, 1993). Therapist judgement can incorporate other operationalisations (e.g., a therapist can decide whether or not the patient has attended for an appropriate duration of treatment, or capture dropout via failure to attend when appropriate). It also arguably has face validity-typical definitions of dropout require a therapist decision in one form or another, although there is also arguably an increased risk of subjective variability in dropout decisions. In order to best represent the available evidence, different operationalisations of dropout were permitted, as long as they captured some measure of unilateral termination after at least one session had been attended, and before a specified treatment completion criterion was met. Rate of dropout and significance of predictors have at times been found to be associated with the measurement used by the study (Pekarik, 1985; Wierzbicki \& Pekarik, 1993). As such, dropout definition was planned as a meta-analysis moderator and subgroup for narrative analysis.

This review included papers published in the ten-year period from June 2010 to June 2020. This decision was influenced by recent changes in contemporary psychological intervention delivery and expansion in thinking around inequality and access (e.g., Delgadillo et al., 2018; Johansson \& Andersson, 2012; Wakefield et al., 2020), and to align with Swift and Greenberg's meta-analysis (2012), which included articles up to June 2010. Focusing on contemporary interventions was a key aspect of this review's design.

\section{Systematic Search and Selection Process}

A systematic electronic database search was supplemented by backward and forward citation searching for eligible studies (Cooper et al., 2018). Databases are listed in Table 2 (Booth, 2016; Gusenbauer \& Haddaway, 2020). Searches were completed by 28 July 2020 . Assessment of studies for inclusion was independently performed by NF and KA/JW and cross checked at each stage.

An example set of search terms is included in Supplementary Material. Generation of search terms was supplemented by collating terms from existing reviews. Reviews were identified by preliminary search [e.g., "(dropout OR attrition
OR etc....) AND review)"] and top reviews selected using impact, relevance, and recency rankings. Relevant search terms from these reviews were then added to the search strategy for this review.

\section{Data Extraction}

Data was extracted by NF using forms (Supplementary Material) adapted from the Cochrane Collaboration data collection form for RCTs and non-RCTs (randomised controlled trials). JW independently verified $10 \%$ of extracted data items. Study authors were contacted where missing data was critical to interpretation of findings. Risk of bias/quality assessment was conducted using the Newcastle-Ottawa quality assessment scale (NOS; Wells et al. 2000) independently by NF and KA. Bias/quality assessments were used to interpret evidence a) on a per study basis, and b) as regards the overall quality of the literature base, and quality was planned as a meta-analysis moderator and subgroup for narrative analysis. For this purpose, study quality was recoded as a 5 level ordinal variable: very low $(0-1)$, low (2-3), moderate (4-5), high (6-7), or very high (8-9) quality. Although funnel plots were planned to assess bias, the Cochrane Handbook advises that they should only be used where meta-analyses include at least 10 studies (Higgins et al., 2019).

\section{Data Synthesis}

Data were narratively synthesised and meta-analysed. Dependent on included studies, planned narrative subgroup comparisons (and meta-analysis subgroups) were as follows: (a) delivery method (face-to-face, telephone, online, other), (b) measure of dropout (e.g., termination-by-failure vs. therapist judgement), (c) measure of deprivation (e.g., income vs. education, individual vs. neighbourhood level), (d) mental health disorder type (e.g., depressive disorders vs. anxiety disorders), and (e) study quality.

Effect sizes and 95\% confidence intervals (CIs) were reported where available, and calculation attempted

Table 2 Databases and search platforms

\begin{tabular}{lll}
\hline Platform & Database(s) & Search type \\
\hline Ovid & Medline & Subject heading and text search \\
Ovid & PsycInfo & Subject heading and text search \\
Web of science & Web of science core collection, BIOSIS citation index, BIOSIS previews, Data & Text search \\
& citation index, KCI-Korean journal database, Russian science citation index, & \\
ProQuest & SciELO citation index & Text search \\
Cochrane library & Social science database, sociology collection & Text search \\
\hline
\end{tabular}


where unavailable. In this review "significance" refers to alpha $=0.05(95 \%)$ two-tailed significance.

Random effects inverse variance meta-analyses were conducted using the metagen function in RStudio (Borenstein et al., 2010; Higgins et al., 2019). Heterogeneity was tested using Cochran's $\mathrm{Q}$ and the $\mathrm{I}^{2}$ statistic. $\mathrm{I}^{2}$ was the primary heterogeneity test, given it is not biased by number of studies. The Cochrane Handbook provide a (rough) guide to interpreting $\mathrm{I}^{2}$ : $0-40 \%$ may not be important; $30-60 \%$ may be moderate heterogeneity; $50-90 \%$ may be substantial heterogeneity; $75-100 \%$ considerable heterogeneity. In contrast, Cochran's Q is underpowered for low numbers of studies, and overpowered for high numbers (Gavaghan et al., 2000; Higgins et al., 2003, 2019), so a $\mathrm{p}$ value of 0.10 was used as recommended (Higgins et al., 2019). Strategies recommended by the Cochrane Handbook to account for heterogeneity were explored as appropriate.

Fig. 1 PRISMA flow diagram of included and excluded studies

\section{Results}

There were 1,379 unique records screened (Fig. 1). There was $96.8 \%$ inter-rater agreement (Cohen's kappa $=0.420$; CI 0.28-0.56, indicating moderate agreement; Landis \& Koch, 1977). Kappa is known to exhibit limitations, particularly where the agreement due to chance is skewed, as in this case. After reaching agreement, there were 45 full texts assessed for eligibility. Inter-rater agreement was $86.7 \%$ (Cohen's kappa $=0.43$; CI 0.07-0.80, moderate agreement). After reaching agreement, three studies were eligible for inclusion.

Backward and forward citation searching of eligible full text articles was performed-after removing duplicates, 166 records were screened. There was $97.6 \%$ inter-rater agreement (Cohen's kappa $=0.83$; CI $0.67-0.99$, indicating almost perfect agreement). After reaching agreement, 14 full texts were assessed for eligibility. Inter-rater agreement was $86.7 \%$ (Cohen's kappa $=0.60$; CI $0.12-1.00$, moderate agreement). After reaching agreement, 2 studies were

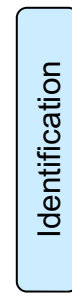

Records identified through

database searching $(n=2249)$

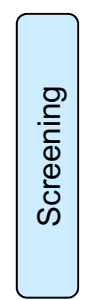

Records after duplicates removed $(n=1379)$
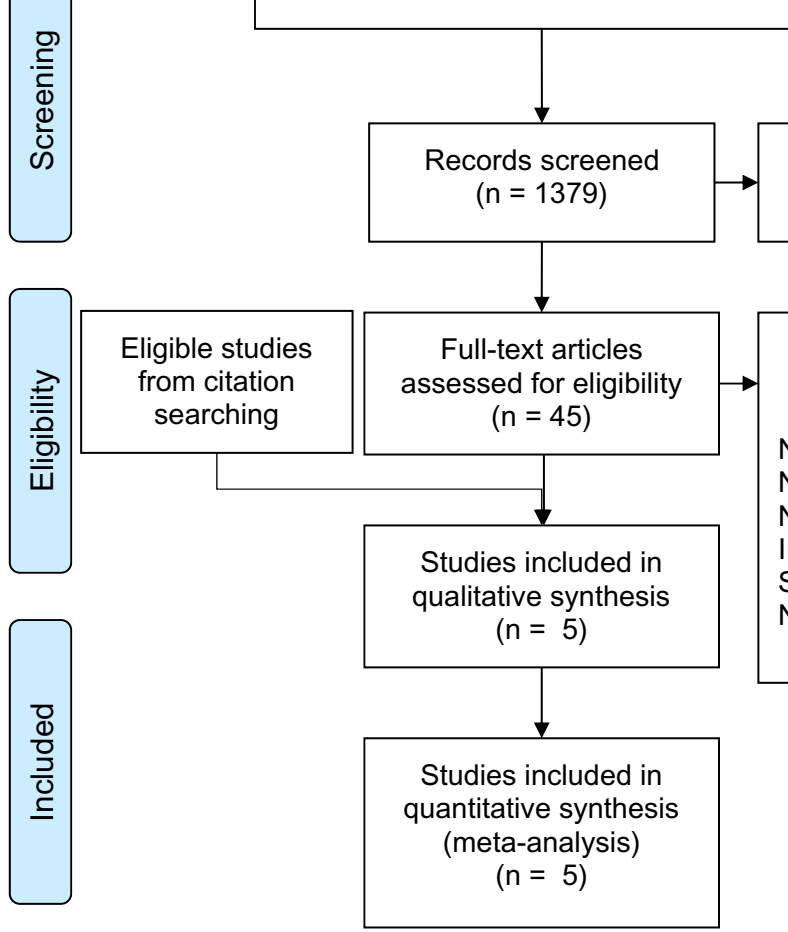

Full-text articles excluded, with reasons $(n=42)$

No deprivation comparison (12) No eligible dropout analysis (11) No eligible CMD intervention (8) Ineligible psychol. intervention (8) Sample includes under 18s (2)

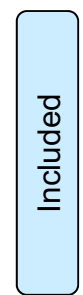
Not peer-reviewed journal article (1) 
eligible for inclusion, giving a total of five studies included in the review.

\section{Summary of Included Studies}

An overview of study characteristics is shown in Table 3. Mean sample size was 170 participants $(S D=100$; range 56 to 308$)$. Mean dropout rate was $32 \%$ ( $S D=10 \%$; range $15-41 \%)$. Average age across studies was between 34 and 50 (one study reported median rather than mean age). Mean percentage of female participants was 68\% (range 10-100\%). White Caucasian participants were the racial/ethnic majority in three of four studies reporting this (mean $60 \%$, range $32-79 \%$ ). Employment status was only reported by one study (Mott et al., 2014; 46\% employment).

All studies delivered interventions face-to-face (two did not explicitly specify, but are strongly inferred due to context). Whilst two studies used a fixed treatment duration (12-13 h; Holder et al., 2019; Lester et al., 2010), the remainder offered more variable treatment duration. There were no co-interventions specified by any study.
Eight deprivation variables were analysed across the five included studies (i.e., some studies used more than one measure of deprivation; Table 4). The majority of studies (four of five) used individual/household level measures of deprivation - these included educational level (four studies), income level (two studies), and employment status (one study). In contrast, Binnie and Boden (2016) used a neighbourhood level measure - the index of multiple deprivation (IMD; Department for Communities \& Local Government, 2011). Measures of deprivation used by more than one study (i.e. education and income) were operationalised both categorically and continuously by different studies.

Regarding measurement of treatment completion/dropout, two studies used duration-based measures (Holder et al., 2019; Lester et al., 2010). Binnie and Boden (2016) used a therapist judgement definition. The final two studies used combinations of therapist judgement and duration-based measures (Mott et al., 2014; Schindler et al., 2013). Schindler et al. (2013) also excluded drop-outs for neutral reasons (such as moving out of area), to produce an outcome they term "quality-associated dropout".

Table 3 Summary characteristics of included studies

\begin{tabular}{|c|c|c|c|c|c|c|c|c|}
\hline $\begin{array}{l}\text { First author } \\
\text { (Year) }\end{array}$ & Design & Target disorder & Population & Country & $\begin{array}{l}N \text { com- } \\
\text { pleters/ } \\
\text { dropouts }\end{array}$ & Dropout \% & Female $\%$ & Intervention \\
\hline Binnie (2016) & Observational & CMDs & Primary care & England & $140 / 61$ & 30.3 & 63.4 & CBT \\
\hline Holder (2019) & $\mathrm{RCT}^{\mathrm{a}}$ & $\begin{array}{l}\text { PTSD (military, } \\
\text { sexual) }\end{array}$ & Veterans & US & $33 / 23$ & 41.1 & 100.0 & $\begin{array}{l}\text { CPT and written } \\
\text { account }\end{array}$ \\
\hline Lester (2010) & $\mathrm{RCT}^{\mathrm{a}}$ & PTSD (violence) & $\begin{array}{l}\text { Female victims of } \\
\text { violence }\end{array}$ & US & 199/109 & 35.4 & 100.0 & $\begin{array}{l}\text { CPT/CT/PE/written } \\
\text { account }\end{array}$ \\
\hline Mott (2014) & Observational & PTSD & Veterans & US & $58 / 33$ & 36.3 & 8.8 & CPT and/or PE \\
\hline Schindler (2012) & Observational & Depression & University clinic & Germany & $164 / 29$ & 15.0 & 68.4 & CBT \\
\hline
\end{tabular}

$C B T$ cognitive behavioural therapy, $C P T$ cognitive processing therapy, $C T$ cognitive therapy, $C M D s$ common mental disorders, $P E$ prolonged exposure, $P T S D$ post-traumatic stress disorder, $R C T$ randomised controlled trial

${ }^{\text {a }}$ Secondary analysis of data from one or more randomised trials

Table 4 Summary of deprivation variables used by included studies

\begin{tabular}{lllll}
\hline First author (year) & Measure & Level & Operationalisation & Summary statistics \\
\hline Binnie (2016) & IMD & Neighbourhood & Binary-Lower vs. higher deprivation than UK average & $74 \%$ lower than UK average \\
Holder (2019) & Education & Individual & Continuous-years of education & Mean 14.4 years $(S D=2.03)$ \\
Lester (2010) & Education & Individual & Continuous-years of education & Mean 14.1 years $(S D=2.28-2.61)$ \\
Mott (2014) & Education & Individual & Binary-post high school educated or not & $59.5 \%$ post high school educated \\
Schindler (2012) & Education & Individual & Binary-more than 12 years of education or not & $44.0 \%$ more than 12 years \\
Lester (2010) & Income & Household & Categorical-6-point annual income scale & Mean $\$ 10,001-20,000$ \\
Mott (2014) & Income & Individual & Continuous-annual income & Mean $\$ 36,000(S D=\$ 27,000)$ \\
Mott (2014) & Employment & Individual & Binary-employed or not & $46.2 \%$ employed \\
\hline
\end{tabular}

Some studies appear more than once due to analysing more than one measure of deprivation

$I M D$ index of multiple deprivation 


\section{Quality and Risk of Bias}

Studies were quality-assessed using the Newcastle-Ottawa quality assessment scale (87\% inter-rater agreement-the more stringent rating was chosen in cases of disagreement). Table 5 shows an overview grid of quality ratings, with rationales for decisions included in Supplementary Material. Mean study quality was 7/9 ("high quality" on average).

Two studies reported missing deprivation data (Lester et al., 2010; Mott et al., 2014; 20 and $\leq 10 \%$, respectively). Sample size was relatively small in some studies, with $<50$ dropouts reported by three of five studies. This limits power to detect effects. None of the five studies reported statements regarding conflicts of interest, risking bias via vested interests. The studies using trial data both reported a range of recruitment methods, reducing the chance of selection bias. Inclusion criteria for these studies were judged to be generally representative of routine practice.

Risk of publication bias was considered low, primarily because the variables of interest to this review were typically control variables in included studies. However, this may increase risk of outcome reporting bias, given deprivation analyses may not always be fully reported. Risk of selection bias was also considered low (see Comparison with excluded studies).

\section{Narrative Synthesis}

An overview of statistical results is shown in Table 6. Associations between deprivation and dropout were tested using uncontrolled analyses (chi-square tests, $t$ tests, or correlation matrices; 6 analyses) and/or controlled regression (5 analyses). Two out of six uncontrolled analyses found significant associations between deprivation and dropout, such that greater deprivation was associated with increased dropout (Binnie \& Boden, 2016; Mott et al., 2014). The remaining four found no significant association. Furthermore, the significant results risk type I errors due to potential confounding from other variables.

After controlling for relevant variables (depression severity, prior inpatient stay, military service era) both of these significant effects became non-significant in logistic

Table 5 Overview of Newcastle Ottawa quality assessment scale ratings

\begin{tabular}{|c|c|c|c|c|c|c|}
\hline & Binnie (2016) & Holder (2019) & Lester (2010) & $\begin{array}{l}\text { Mott (2014) } \\
\text { (education vari- } \\
\text { able) }\end{array}$ & $\begin{array}{l}\text { Mott (2014) (income } \\
\& \text { employment vari- } \\
\text { ables) }\end{array}$ & Schindler (2012) \\
\hline \multicolumn{7}{|l|}{ Selection } \\
\hline $\begin{array}{l}\text { Representative- } \\
\text { ness of exposed } \\
\text { cohort }\end{array}$ & $*$ & $*$ & $*$ & $*$ & $*$ & $*$ \\
\hline $\begin{array}{l}\text { Non-exposed } \\
\text { cohort selection }\end{array}$ & $*$ & $*$ & $*$ & $*$ & $*$ & * \\
\hline $\begin{array}{l}\text { Ascertainment of } \\
\text { exposure }\end{array}$ & $\begin{array}{l}\text { No explicit descrip- } \\
\text { tion }\end{array}$ & Written self-report & $*$ & $*$ & $*$ & No description \\
\hline $\begin{array}{l}\text { Outcome of inter- } \\
\text { est not present at } \\
\text { start of study }\end{array}$ & $*$ & $*$ & $*$ & $*$ & $*$ & $*$ \\
\hline \multicolumn{7}{|l|}{ Compar-ability } \\
\hline $\begin{array}{l}\text { Comparability of } \\
\text { cohorts-did } \\
\text { study control for } \\
\text { a key variable ( } 1 \\
\text { point) and for any } \\
\text { additional vari- } \\
\text { able (1 point) }\end{array}$ & $* *$ & $* *$ & $*$ & $* *$ & $\begin{array}{l}\text { Not for these vari- } \\
\text { ables }\end{array}$ & $\begin{array}{l}\text { Not for deprivation } \\
\text { variable }\end{array}$ \\
\hline \multicolumn{7}{|l|}{ Outcome } \\
\hline $\begin{array}{l}\text { Assessment of } \\
\text { outcome }\end{array}$ & $*$ & $*$ & No description & $*$ & $*$ & No description \\
\hline $\begin{array}{l}\text { Follow-up long } \\
\text { enough }\end{array}$ & $*$ & $*$ & $*$ & $*$ & $*$ & $*$ \\
\hline $\begin{array}{l}\text { Adequate follow- } \\
\text { up }\end{array}$ & $*$ & $*$ & $*$ & $*$ & $*$ & * \\
\hline Total score (quality) & 8/9 Very high & 8/9 Very high & 7/9 High & 9/9 Very high & 7/9 High & 5/9 Moderate \\
\hline
\end{tabular}

Asterisks indicate scores of 1 (or 2), and Italic values indicate scores of 0 for the associated item. Mott (2014) appears twice, as it attained different scores for different deprivation variables 
Table 6 Statistical results from included studies

\begin{tabular}{|c|c|c|c|}
\hline First author (year) & Measure of deprivation & Dropout definition & Summary results \\
\hline Binnie (2016) & IMD & TJ & $\begin{array}{l}\text { Uncontrolled chi-square analysis found that below average } \\
\text { neighbourhood deprivation was significantly more com- } \\
\text { mon in completers }(78 \%) \text { compared with dropouts }(64 \%) \text {. } \\
\chi^{2}(1)=4.24, p=0.039 . \text { However, logistic regression found } \\
\text { that only depression severity remained significant as a dropout } \\
\text { predictor (IMD was non-significant) }\end{array}$ \\
\hline \multirow[t]{2}{*}{ Holder (2019) } & Education (years) & $<6$ Sessions & $\begin{array}{l}\text { Uncontrolled correlation matrix ( } \mathrm{p} \geq 0.05, \mathrm{r}=0.21 \text { ) and logistic } \\
\text { regression ( } \mathrm{p}>0.010 \text {, controlling for treatment outcome } \\
\text { expectations and negative cognitions) both non-significant }\end{array}$ \\
\hline & & Sessions (out of 12) attended ${ }^{a}$ & $\begin{array}{l}\text { Uncontrolled correlation matrix ( } \mathrm{p} \geq 0.05, \mathrm{r}=0.23 \text { ) and multiple } \\
\text { regression ( } \mathrm{p}>0.010 \text {, controlling for treatment outcome } \\
\text { expectations and negative cognitions) both non-significant }\end{array}$ \\
\hline Lester (2010) & Education (years) & $<$ Full protocol & $\begin{array}{l}\text { Logistic regression }(B=0.81, \text { OR } 0.93,95 \% \text { CI } 0.80-1.06, \\
Z=-1.08, \\
p=0.28) \text { was non-significant after controlling for race, age, } \\
\text { income, abuse history, treatment outcome expectations }\end{array}$ \\
\hline Mott (2014) & Education (> high school) & TJ or $<7$ sessions & $\begin{array}{l}\text { Uncontrolled chi-square analysis }\left(\chi^{2}(1)=3.97, \mathrm{p}<0.05\right) \text { found } \\
\text { that post-high school education was significantly more com- } \\
\text { mon in completers }(67 \%) \text { compared with dropouts }(45 \%) \text {. } \\
\text { However, Logistic regression was non-significant after control- } \\
\text { ling for prior inpatient psychiatric stay and military service era }\end{array}$ \\
\hline Schindler (2012) & Education (> 12 years) & $\mathrm{TJ}$ and $<$ allowed sessions & $\begin{array}{l}\text { Uncontrolled chi-square analysis }\left(\chi^{2}(1)=1.46, p>1.00\right) \text { was } \\
\text { non-significant. Variable was therefore not entered into logistic } \\
\text { regression }\end{array}$ \\
\hline Lester (2010) & Household income & $<$ Full protocol & $\begin{array}{l}\text { Logistic regression }(B=0.68, \text { OR } 0.79,95 \% \text { CI } 0.62-1.00 \text {, } \\
\mathrm{Z}=-2.00, \mathrm{p}=0.05) \text { marginally reached significance after } \\
\text { controlling for race, age, education, abuse history, treatment } \\
\text { outcome expectations. Increased income was associated with } \\
\text { reduced odds of dropout }\end{array}$ \\
\hline Mott (2014) & Participant's income & $\mathrm{TJ}$ or $<7$ sessions & $\begin{array}{l}\text { Uncontrolled t-test analysis }(t=0.75, \mathrm{p}>0.05) \text { was non-signifi- } \\
\text { cant. Variable was therefore not entered into logistic regression }\end{array}$ \\
\hline Mott (2014) & Employment status & $\mathrm{TJ}$ or $<7$ sessions & $\begin{array}{l}\text { Uncontrolled chi-square analysis }\left(\chi^{2}(1)=1.46, \mathrm{p}>0.05\right) \text { was } \\
\text { non-significant. Variable was therefore not entered into logistic } \\
\text { regression }\end{array}$ \\
\hline
\end{tabular}

Some studies appear more than once due to analysing more than one measure of deprivation

$I M D$ index of multiple deprivation, $T J$ therapist judgement

${ }^{\mathrm{a}}$ Continuous variable

regression analyses. In total, only one out of five logistic regression analyses found that greater deprivation was significantly independently associated with increased dropout (Lester et al., 2010). The effect only marginally reached significance $[Z$ score $=2.00, O R 1.27(1.00-1.61), \mathrm{p}=0.05]$. This effect was only significant for one of the two measures of deprivation analysed by that study (household income, but not education). The study did not control for symptom severity, which may have accounted for a proportion of variance apparently associated with deprivation, as in Binnie and Boden (2016). There was also 20\% missing deprivation data reported, further limiting confidence. As such, on average the reviewed literature did not suggest a significant effect of deprivation on dropout.

The study reporting a significant controlled effect (Lester et al., 2010) had the largest sample size (over twice the average sample size of the other studies), and may have had more power to detect an effect, even accounting for missingness of data. It was the only study to analyse a householdlevel measure of deprivation, but otherwise was relatively similar to other included studies (a North American study of a cognitive processing therapy intervention targeting PTSD). Lester et al. (2010) defined dropout as not completing the full treatment protocol and post-treatment assessment. Because they do not describe the post-treatment assessment in detail, it is difficult to know whether this criterion may have affected dropout.

Three measures of deprivation were not included in studies' logistic regression analyses, due to non-significance in uncontrolled analyses. Due to potential negative confounding effects, it cannot be assumed that these variables would have also been non-significant in a full logistic regression. 
Dropout rates and significance of effects did not appear to be systematically different for studies using RCT data compared with observational studies.

\section{Narrative Sub-group Comparisons}

Because only one study found a significant independent (controlled) effect of deprivation, the scope for sub-group comparisons is limited. As such, although planned subgroup comparisons are presented in full in Supplementary Material, they are only briefly summarised here. Regarding deprivation measure, results from this review generally indicated no significant effect of education $(k=4)$. Other deprivation measures were reported by only 1-2 studies each. Regarding delivery modality, all included interventions were delivered face-to-face. Results may not therefore generalise to other modes of delivery. No clear patterns emerged between categories of mental health disorder, study quality, or dropout measure.

\section{Meta-Analysis}

Controlled effects were preferred for the purposes of metaanalysis. Although only one study reported the required controlled effect size statistics (Lester et al., 2010), after contacting remaining authors by email, two further authors provided the required data (Binnie \& Boden, 2016; Holder et al., 2019).

An overall meta-analysis of controlled effects of deprivation on dropout was performed using the three studies with relevant data (Binnie \& Boden, 2016; Holder et al., 2019;
Lester et al., 2010). As Lester et al. (2010) analysed both education and household income, two alternative analyses were performed (Fig. 2). Using household income in Lester et al. (2010), the overall effect was significant, such that greater deprivation was associated with increased odds of dropout, OR 1.32 (1.05-1.67), $\mathrm{p}=0.019$, with very low heterogeneity indicated by relevant tests, $\mathrm{I}^{2}=0 \%(0-77 \%)$, $\mathrm{Q}=0.89, \mathrm{p}=0.642$. Substituting education in Lester et al. (2010), the overall effect was non-significant, OR 1.21 (0.92-1.59), $\mathrm{p}=0.172$. Heterogeneity was greater in this analysis, $\mathrm{I}^{2}=24 \%(0-92 \%), \mathrm{Q}=2.62, \mathrm{p}=0.270$, although both $\mathrm{I}^{2}$ confidence intervals were broad.

Although controlled effect sizes were preferable, there were generally more studies reporting uncontrolled effect sizes, so meta-analyses of both are presented. An overall meta-analysis of uncontrolled effect of deprivation on dropout from four studies is presented in Fig. 3. Each of Mott et al.'s (2014) three measures of deprivation was metaanalysed separately. Using education (highest uncontrolled effect size) resulted in a significant overall uncontrolled effect of deprivation, such that greater deprivation was associated with increased odds of dropout, OR 1.76 (1.08-2.87), $\mathrm{p}=0.024$ (Fig. 3, Panel A). Tests indicated minimal heterogeneity, but broad confidence intervals $\left[\mathrm{I}^{2}=3 \%(0-85 \%)\right.$, $\mathrm{Q}=3.09, \mathrm{p}=0.378$ ].

Using income [lowest model heterogeneity, $\mathrm{I}^{2}=0 \%$ $(0-81 \%), Q=2.45, \mathrm{p}=0.484]$ resulted in a non-significant overall uncontrolled effect, OR 1.55 (0.98-2.43), $\mathrm{p}=0.059$ (Fig. 3, Panel B). Similarly, using employment status [highest model heterogeneity, $\mathrm{I}^{2}=49 \%(0-83 \%), \mathrm{Q}=5.91$, $\mathrm{p}=0.116]$ also resulted in a non-significant effect, OR 1.28
Fig. 2 Meta-analyses of overall controlled effects of deprivation on dropout, using alternate measures of deprivation from Lester et al. (2010) in panel A and panel $\mathrm{B}$
A Study

Binnie (2016): IMD

Holder (2019): Less Educated

Lester (2010): Lower Income

Random effects model Heterogeneity: $I^{2}=0 \%, p=0.64$

B Study

Binnie (2016): IMD

Holder (2019): Less Educated Lester (2010): Less Educated

Random effects model Heterogeneity: $I^{2}=24 \%, p=0.27$
Odds Ratio

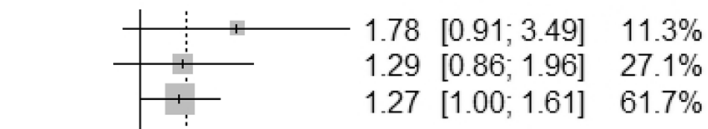

0.5

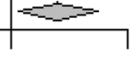

1

Odds Ratio

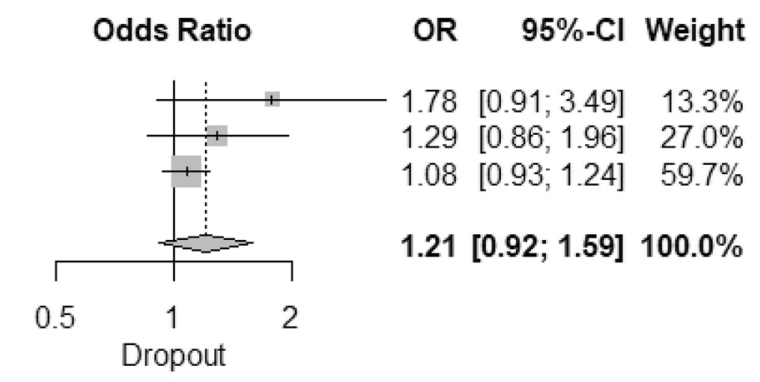

$1.32[1.05 ; 1.67] 100.0 \%$ 2 (n)

Note: IMD = index of multiple deprivation. 
Fig. 3 Meta-analyses of overall uncontrolled effects of deprivation on dropout, using alternate measures of deprivation from Mott et al. (2014) in panel A and panel B
A Study Odds Ratio OR $\quad 95 \%-\mathrm{Cl}$ Weight Binnie (2016): IMD Holder (2019): Less Educated Mott (2014): Less Educated Schindler (2012): Less Educated

Random effects model Heterogeneity: $I^{2}=3 \%, p=0.38$

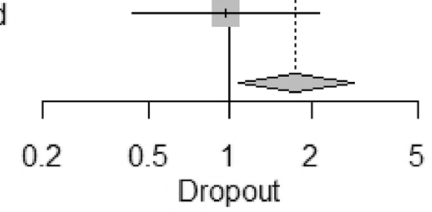

B Study

Binnie (2016): IMD Holder (2019): Less Educated Mott (2014): Lower Income Schindler (2012): Less Educated

Random effects model Heterogeneity: $I^{2}=0 \%, p=0.48$

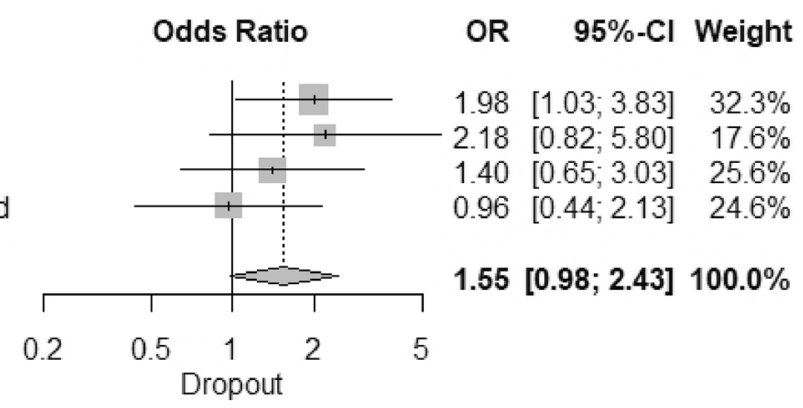

Note: IMD = index of multiple deprivation.
(0.70-2.34), $\mathrm{p}=0.423$ (not pictured). Because of the disparity in results, a sensitivity analysis was conducted, excluding Mott et al. (2014). This was also non-significant, OR 1.60 (0.91-2.81), $\mathrm{p}=0.105$ (not pictured).

Thus, meta-analytic evidence for a general effect of deprivation (controlled or uncontrolled) is mixed. In both cases the effect crosses the threshold for significance depending on the measure of deprivation analysed by those studies using more than one measure. There does not appear to be a consistent trend (in particular, income but not education was significant in Lester et al., 2010 in the controlled analysis, and vice versa for Mott et al., 2014 in the uncontrolled analysis).

\section{Subgroup Meta-Analyses}

As in the narrative synthesis, although subgroup metaanalyses and comparisons were planned, these were mostly unfeasible and/or uninterpretable due to low numbers of studies in each subgroup and risk of confounding. Only one subgroup (education) comprised more than 2 effects suitable for meta-analysis - this is therefore the only subgroup analysis tentatively reported here. Meta-analysis of the uncontrolled effect of education $(k=3)$ was non-significant, OR $1.67(0.87-3.20), \mathrm{p}=0.121\left[\mathrm{I}^{2}=30 \%(0-93 \%), \mathrm{Q}=2.87\right.$, $\mathrm{p}=0.238]$.

\section{Comparison with Excluded Studies}

Because of the low number of included studies, and the conservative inclusion criteria utilised, results from included studies were briefly compared with those from excluded studies. A comparative set of excluded studies was derived, including those studies that (a) were excluded during fulltext assessment (i.e. passed initial screening), and (b) included an analysis of the effect of deprivation on dropout from individual psychological intervention for CMDs. In other words, although these studies still assessed the same broad topic, the stricter aspects of inclusion criteria were not enforced, giving a wider, more heterogeneous set of studies.

There were 15 studies in this comparator set ( 8 from database searching and 7 from citation searching; full list in Supplementary Material). Primary reasons for exclusion from the main review were: no clear exclusion of non-starters from the definition of dropout $(n=9)$, sample included a mix of both individual and group intervention participants $(n=4)$, or no clear differentiation between treatment dropout and study dropout $(n=2)$.

In summary, 6/14 uncontrolled analyses were significant, and 6/11 controlled analyses were significant. Three factors are briefly considered: reason for exclusion, deprivation measure, and target disorder.

Excluded comparator studies that may have included nonstarters reported significant effects in 7/13 analyses (including 5/9 controlled analyses). Samples contaminated by group intervention participants reported significant effects in $4 / 6$ analyses. Studies that did not differentiate treatment and study dropout reported significant effects in $0 / 3$ analyses.

All 15 excluded comparator studies analysed the effect of education-7/15 found significant effects of education (including 4/9 controlled analyses). Two studies analysed the 
effect of income-both uncontrolled analyses were significant. Five studies analysed the effect of employment-2/5 were significant (including 2/2 controlled analyses). One study analysed the effect of socio-economic status-this uncontrolled analysis was non-significant.

As regards analyses in depression studies, 7/14 were significant. There were 3/5 significant effects in PTSD study analyses, and 1/4 significant effects in anxiety study analyses.

This comparison suggests that overall findings in the broader contemporary literature are also uncertain, although significant effects of deprivation may be more common compared with studies included in this review. Including non-starters and/or participants receiving group intervention may be associated with increased effects of deprivation, compared with the included literature that focused only on those who have already begun to attend treatment and are receiving individual treatment only. Inconclusive and tentative hints of differential effects according to deprivation measure or target disorder that were found in this review are also reflected in the broader literature.

\section{Discussion}

This review aimed to assess the evidence for an effect of deprivation on dropout from contemporary psychological intervention for common mental disorders. Overall, evidence was inconclusive, based on five eligible studies. Narrative synthesis predominantly suggested no significant effect, especially after controlling for other covariates. Significance of meta-analyses varied according to the measure of deprivation in those studies that analysed multiple measures, and as such were uncertain.

Our findings contrast with older reviews (Baekeland \& Lundwall, 1975; Garfield, 1994; Wierzbicki \& Pekarik, 1993) that found mostly significant effects of variables such as socio-economic status, education, occupation, and income, but used broader dropout definitions and populations (for example, including people with severe mental illness and those receiving inpatient treatment).

In contrast, our results are more consistent with Swift and Greenberg's (2012) more recent meta-regression, which found no significant effect of employment or education, despite also including broader clinical populations than the current review. One hypothesis is that changes to service provision or other factors over time have reduced the effect of deprivation on dropout, for example via initiatives to improve access to psychological interventions.

Research and review methods may also have improved over time. Wierzbicki and Pekarik (1993) note the potential for reporting bias to have inflated apparent effects, particularly in earlier studies. The relatively basic search terms and strategies used in earlier reviews (where reported) may also have led to selection bias. Both Baekeland and Lundwall (1975) and Garfield (1994) are particularly limited by current standards, with overwhelmingly opaque review methods, search strategies, and inclusion criteria. Garfield (1994) recognises that most studies in their review were of low quality. Wierzbicki and Pekarik's (1993) approach to meta-analysis has also been challenged subsequently (Swift \& Greenberg, 2012).

Furthermore, Baekeland and Lundwall's (1975) review of adult outpatient psychotherapy studies found significant deprivation effects only for individually delivered psychoanalytic psychotherapy studies-no significant effects were detected for non-psychoanalytic studies (Baekeland \& Lundwall, 1975). In contrast, the studies included in this review (and the majority of those in Swift \& Greenberg, 2012) primarily used cognitive/cognitive-behavioural treatment orientations. This may indicate a moderating effect of treatment orientation-further investigation is warranted.

A relatively small effect of deprivation that is difficult to detect without suitable power is also a possibility. This interpretation is supported by the fact that sample size in this review was relatively small on average, particularly for participants who dropped out of treatment (around 50 on average per study). Consistent with this, the only significant controlled effect was detected by the study that had over double the average sample size of other studies (Lester et al., 2010). However, this contrasts with Swift and Greenberg's (2012) meta-analysis, which was extremely highly powered. Explanations may relate to the broad range of clinical contexts they included, and/or to the measures of deprivation they did and did not analyse. In other words, there may also be differential effects. It is partly for this reason that carefully focused reviews are needed.

Deprivation itself is a multi-faceted concept, and proximal or distal indicators may demonstrate differing associations. Furthermore, a single measure may have differential effects under different treatment conditions. This was anticipated, and sub-group comparisons were planned and analysed where possible. However, the small number of studies and risk of study-level confounding made it difficult to draw firm conclusions. Education was most consistently analysed in the included studies-narrative and meta-analytic evidence from this review did not support a significant effect of education on dropout. This is consistent with Swift and Greenberg (2012), as well as a recent review and meta-analysis that found that education was a poorer predictor of clinical outcome than other deprivation measures (Finegan et al., 2018). Even Garfield (1994) reported inconsistent effects in their relatively more recent studies. Education was used in $50 \%$ of analyses in the current review, meaning our results may be biased towards this measure. It was not possible to draw 
meaningful conclusions regarding other specific measures of deprivation in the current review. It was also difficult to draw conclusions regarding target CMD, dropout definition, treatment delivery modality, or quality, in part due to risk of confounding.

This review aimed to use comprehensive search terms and inclusive supplementary search methods. As such, the low number of included studies was surprising. However, an earlier 15-year meta-analysis of dropout from individual psychotherapy (Sharf et al., 2010) also struggled to include eligible deprivation analyses, finding only one study providing usable effect size data (Sharf, 2009). The low number of included studies may be related to stringent inclusion criteria. These criteria were designed to produce relative homogeneity in the included study set, while limiting the potential for confounding by related concepts. In particular, differentiation was made in this review between treatment non-initiation and dropout. Failure to clarify this was the most common reason that studies otherwise meeting PICOSS criteria were excluded from the review. Including these would have tripled the number of included studies, but risked confounding with failure to initiate. Even then, a significant controlled effect would only have been found in 50\% of studies. Tentative comparison of included and excluded studies suggests that it may be beneficial for future reviews to explore the potential for differential effects between noninitiators and dropouts, and/or between participants receiving group and individual intervention. There are indications from this review that conflating in-treatment dropout and non-initiation may potentially lead to inaccurate conclusions about deprivation and dropout.

Another potential impact of the highly selected set of studies included in the current review is the risk of selection bias, particularly regarding excluding internet-delivered interventions. For example, there were three internet-delivered intervention studies excluded primarily due to a failure to distinguish non-initiators from dropouts (although in practice their results were comparable to included studies). The concept of attending at least one session is arguably less intuitive for internet-delivered interventions, given they don't typically involve sessions in the traditional sense. A comparable concept would be to specify that participants accessed the intervention at least once, or completed at least one module/chapter/video, and studies would have been included had they specified this. This could be specified in future studies, if only as a sensitivity analysis. Concepts such as attendance and dropout arguably begin to change meaning for some internet-based interventions, where therapist judgement may be inapplicable, and content may be accessed ad hoc according to patient need rather than scheduled between two parties. However, this also underscores the need for robust syntheses to compare and contrast effects across different modalities of delivery. Unfortunately, although it was an aim of this review, it was not possible in practice due to a lack of eligible studies.

Interestingly, a primary data meta-analysis with a narrow focus specifically on internet-based unguided cognitive behavioural therapy interventions for depression found that lower education level but not employment status predicted dropout (Karyotaki et al., 2015). Although dropout was again potentially confounded with treatment non-initiation, this could alternatively suggest that there may be a differential effect according to treatment modality. This is intuitive-for example, internet-based interventions may rely relatively more on literacy and information technology skills, increasing the salience of educational level (Waller \& Gilbody, 2009). In comparison, face-to-face interventions require patients to travel to sessions, potentially requiring money for transport, child-care, etc. As such, factors such as income may be stronger predictors for face-to-face interventions.

One of the reasons for undertaking the present review was to attempt to capture emerging modalities such as internet and telephone based treatments. The failure to include studies in these areas is therefore troubling. Dropout is a major concern for internet treatments (from 10 unguided internet intervention RCTs, $40 \%$ of patients dropped out in the first quarter of treatment, with $70 \%$ dropout before completion of three quarters of modules; Karyotaki et al., 2015). It is therefore strongly recommended that future research into internet treatments in particular separates non-initiators from treatment dropouts, in order to improve understanding of what may be distinct processes.

Another contributory factor to the low number of included studies may be related to study design and reporting. Deprivation was not typically an explicit focus of the included and screened studies. Furthermore, typical measures of interest to this review were often included only as part of a range of control variables, and reported only in passing or in aggregate. This makes systematic assessment for inclusion particularly challenging. We were aware of this and aimed to err towards inclusivity when screening papers. Despite this, it is likely that some studies including relevant data were not identified. This is supported by the relatively high proportion of eligible studies identified through citation searching. The propensity for deprivation to be included only as a control variable also risks reporting bias. This was noted by Wierzbicki and Pekarik (1993), who found that up to $25 \%$ of demographic variable effect sizes could not be included in their meta-analysis due to insufficient reporting, and cautioning that their mean effects should be considered as upper bounds for true effects.

Another methodological limitation of the included literature was a failure to include deprivation measures in controlled analyses when they were non-significant in uncontrolled analyses. This increases the risk of type II error due 
to potential negative confounding in uncontrolled analyses, reduces the number of controlled analyses eligible for meta-analysis, and increases selection bias in the controlled analyses.

Similar to previous meta-analyses (Swift \& Greenberg, 2012; Wierzbicki \& Pekarik, 1993), there was variation in dropout rates across studies included in this review-in particular, four studies reported around 30-40\% dropout whilst one reported $15 \%$. Ironically, the outlier in our study was closest to Swift and Greenberg's (2012) weighted mean dropout rate of $20 \%$, whilst the remaining studies were comparable to Wierzbicki and Pekarik's (1993) mean dropout rate of $47 \%$. Both previous meta-analyses also reported wide variation in dropout (Swift \& Greenberg range $=0-74 \%$, Wierzbicki \& Pekarik $S D=22 \%$ ). Swift and Greenberg (2012) posit that these differences may reflect underlying covariates affecting dropout, although Wierzbicki and Pekarik (1993) also identified dropout operationalisation as a factor. The outlier study in this review used a relatively more conservative operationalisation of dropout, although the underlying components were consistent theoretically and practically with the broader dropout literature.

\section{Clinical Implications}

Evidence from the current review is limited, with potential indications of differential effects despite overall negative or inconclusive findings. As such, clinic managers can neither assume nor rule out a contribution of deprivation to dropout from intervention, particularly as regards their specific clinical context. Results from this review also cannot be assumed to apply to treatment initiation-only to dropout subsequent to initiation.

Variables related to mental health severity and treatment expectations appeared to be stronger predictors of dropout than deprivation in controlled analyses. Care should be taken when interpreting these findings. In particular, causal relationships between these factors may be complex-for example, see social selection and social causation theories of mental health (Dohrenwend et al., 1992; Mossakowski, 2014). Treatment expectations may also be influenced by the individual's socioeconomic position, with recent evidence indicating that therapeutic pessimism is greater for people experiencing deprivation (Potts \& Henderson, 2020). Thus, although other variables may have better pragmatic predictive power for therapists and other front-line staff, policy makers should not yet discount deprivation as a potential contributory causal factor without more comprehensive evidence.

Clinics should also consider the choice of measures related to deprivation that they collect in routine clinical practice. Evidence suggests that education may be a weaker predictor of dropout and clinical outcome in contemporary face-to-face interventions, compared with other measures with more mixed predictive power. In addition to potentially differential effects according to delivery modality, effects may also vary by clinical context—clinics may benefit from conducting their own suitably powered context-specific evaluations, particularly as landscapes and policies regarding both clinical delivery and socio-economic inequality continue to evolve over time (e.g., Oates \& Firth, 2020).

\section{Future Research Directions}

Despite considerable literature investigating dropout covariates, there was only a very limited set of studies meeting inclusion criteria for this review. This was unexpected, and prevented us from fully utilising certain pre-planned analyses. We believe a picture may be emerging indicating differential effects of deprivation on dropout depending on context. As such a challenge for future reviewers may be how to balance homogeneity and applicability to current practice against sufficient included studies to make confident conclusions.

Future research (and practice) should continue to recognise that dropout may be defined in different ways, particularly as interventions evolve (for example, describing dropout from novel modalities and self-directed interventions). This can alter recorded rates of dropout and affect corresponding statistical results (Kaltenthaler et al., 2008; Richards \& Richardson, 2012).

We recommend that deprivation variables included in analyses are clearly reported in titles and abstracts where possible. We also recommend that researchers clearly report their operationalisation of dropout, particularly regarding whether or not non-initiators are included as dropouts. Where they are included, a sensitivity analysis is strongly recommended with non-initiators analysed separated or excluded. Internet interventions might measure initiation by module views or access logs, etc. Similarly, individual and group intervention samples should be reportedly separately.

Studies that test deprivation measures in bivariate (uncontrolled) analyses should include them in multivariate analyses-again, if only as a secondary or sensitivity analysis. Open access data could also allow reviewers to more easily interrogate data to answer questions that were not asked at the time of the study. Results should be clearly reported (e.g., effect sizes, confidence intervals or standard errors and exact $p$ values). Sample sizes should also be of sufficient power to detect potentially small effect sizes. Future research may benefit from looking beyond education to also consider other indicators of deprivation.

The American Psychological Association (APA) made recommendations for measuring markers of socioeconomic status almost fifteen years ago. Recommendations regarding education include measuring both the highest degree 
attained and years of education (American Psychological Association, 2007). The APA (2007) also suggest that wealth is a better measure than income at a specific point in time. They acknowledge that occupation can be more difficult to measure and that employment status as an alternative can provide useful information. Studies included in this review varied as regards concordance with these recommendations, most notably measuring income rather than wealth. Future studies (and clinical organisations) may benefit from considering these recommendations.

Contemporary studies designed directly to investigate the impact of deprivation are greatly needed. These studies could seek to differentiate between indicators of deprivation, as well as investigate potential causality and mediation effects with common predictors such as symptom severity and treatment expectations (Kling et al., 2007). Whilst a review specifically focused on the association between deprivation and non-initiation would also be warranted, any such review may encounter similar problems regarding sufficient contemporary studies. Finally, given our experience that deprivation variables are frequently not the main focus of studies and are only tangentially reported or understated, future reviews may consider hand-searching the full texts of a broader range of dropout studies (i.e. not searching specifically for deprivation-related terms), bearing in mind the need to factor in the greatly increased resource cost of such an approach.

\section{Conclusions}

This review found that measures of deprivation tend not to predict dropout from contemporary face-to-face CMD interventions. However, the set of included studies was small, limiting confidence in these findings. More research is needed, and future studies need to clearly report both their definitions of dropout and their analyses of deprivation measures. Triangulation of evidence suggests that there may be differential effects according to clinical and methodological factors.

Supplementary Information The online version contains supplementary material available at https://doi.org/10.1007/s10488-021-01178-8.

Author Contributions NF-conception and design, literature search, data extraction/quality rating, data analysis, manuscript. MB, JD, AOC - conception and design, manuscript. KA, JW-literature search, data extraction/quality rating, manuscript.

Funding This review was funded by a National Institute for Health Research (NIHR) Clinical Doctoral Research Fellowship (ICA-CDRF2018-04-ST2-043). The funders have had no role in the systematic review. Certain data pertaining to Binnie and Boden (2016) and Holder et al. (2019) were supplied directly from the corresponding authors.

\section{Declarations}

Conflict of interest The authors report no conflict or competing interest in relation to this work.

Ethical Approval This is a review article-no ethical approval was required. The review was conducted and reported in accordance with the preferred reporting items forsystematic reviews and meta-analyses (PRISMA) guidelines.

Research Involving Human and Animal Participants The article did not involve human participants or animals.

Informed Consent The article did not require informed consent.

Open Access This article is licensed under a Creative Commons Attribution 4.0 International License, which permits use, sharing, adaptation, distribution and reproduction in any medium or format, as long as you give appropriate credit to the original author(s) and the source, provide a link to the Creative Commons licence, and indicate if changes were made. The images or other third party material in this article are included in the article's Creative Commons licence, unless indicated otherwise in a credit line to the material. If material is not included in the article's Creative Commons licence and your intended use is not permitted by statutory regulation or exceeds the permitted use, you will need to obtain permission directly from the copyright holder. To view a copy of this licence, visit http://creativecommons.org/licenses/by/4.0/.

\section{References}

American Psychological Association. (2007). Report of the APA task force on socioeconomic status. https://www.apa.org/pi/ses/resou rces/publications/task-force-2006.pdf

Baekeland, F., \& Lundwall, L. (1975). Dropping out of treatment: A critical review. Psychological Bulletin, 82(5), 738-783. https:// doi.org/10.1037/h0077132

Barrett, M. S., Chua, W. J., Crits-Christoph, P., Gibbons, M. B., \& Thompson, D. (2008). Early withdrawal from mental health treatment: Implications for psychotherapy practice. Psychotherapy, 45(2), 247-267. https://doi.org/10.1037/0033-3204.45.2.247

Bartley, M., \& Blane, D. (1994). Appropriateness of deprivation indexes must be ensured. British Medical Journal, 309(6967), 1479-1479. https://doi.org/10.1136/bmj.309.6967.1479

Berzins, S., Babins-Wagner, R., \& Hyland, K. (2018). Relationship of employment status and socio-economic factors with distress levels and counselling outcomes during a recession. Counselling \& Psychotherapy Research, 18(2), 122-132. https://doi.org/10. 1002/capr. 12164

Binnie, J., \& Boden, Z. (2016). Non-attendance at psychological therapy appointments. Mental Health Review Journal, 21(3), 231-248. https://doi.org/10.1108/mhrj-12-2015-0038

Booth, A. (2016). Over $85 \%$ of included studies in systematic reviews are on MEDLINE. Journal of Clinical Epidemiology, 79, 165166. https://doi.org/10.1016/j.jclinepi.2016.04.002

Borenstein, M., Hedges, L. V., Higgins, J. P. T., \& Rothstein, H. R. (2010). A basic introduction to fixed-effect and random-effects models for meta-analysis. Research Synthesis Methods, 1(2), 97-111. https://doi.org/10.1002/jrsm.12

Brandt, L. W. (1965). Studies of "dropout" patients in psychotherapy: A review of findings. Psychotherapy, 2(1), 6-12. https://doi.org/ $10.1037 / \mathrm{h} 0088610$ 
Cahill, J., Barkham, M., Hardy, G., Rees, A., Shapiro, D. A., Stiles, W. B., \& Macaskill, N. (2003). Outcomes of patients completing and not completing cognitive therapy for depression. British Journal of Clinical Psychology, 42, 133-143. https://doi.org/10. 1348/014466503321903553

Clark, D. M., Canvin, L., Green, J., Layard, R., Pilling, S., \& Janecka, M. (2018). Transparency about the outcomes of mental health services (IAPT approach): An analysis of public data. The Lancet, 391(10121), 679-686. https://doi.org/10.1016/s0140-6736(17) 32133-5

Cookson, R., Asaria, M., Ali, S., Shaw, R., Doran, T., \& Goldblatt, P. (2018). Health equity monitoring for healthcare quality assurance. Social Science \& Medicine, 198, 148-156. https://doi.org/ 10.1016/j.socscimed.2018.01.004

Cooper, A. A., \& Conklin, L. R. (2015). Dropout from individual psychotherapy for major depression: A meta-analysis of randomized clinical trials. Clinical Psychology Review, 40, 57-65. https://doi.org/10.1016/j.cpr.2015.05.001

Cooper, C., Lovell, R., Husk, K., Booth, A., \& Garside, R. (2018). Supplementary search methods were more effective and offered better value than bibliographic database searching: A case study from public health and environmental enhancement. Research Synthesis Methods, 9(2), 195-223. https://doi.org/10.1002/jrsm.1286

Davison, G. C. (2000). Stepped care: Doing more with less? Journal of Consulting and Clinical Psychology, 68(4), 580-585. https:// doi.org/10.1037//0022-006x.68.4.580

Delgadillo, J., Asaria, M., Ali, S., \& Gilbody, S. (2016). On poverty, politics and psychology: The socioeconomic gradient of mental healthcare utilisation and outcomes. British Journal of Psychiatry, 209(5), 431-432. https://doi.org/10.1192/bjp.bp. 115.171017

Delgadillo, J., Farnfield, A., \& North, A. (2018). Social inequalities in the demand, supply and utilisation of psychological treatment. Counselling and Psychotherapy Research, 18(2), 114-121. https:// doi.org/10.1002/capr.12169

Department of Health. (2008). IAPT implementation plan: National guidelines for regional delivery. Retrieved from http://www.iapt. nhs.uk/silo/files/implementation-plan-national-guidelines-forregional-delivery.pdf

Department of Health. (2011). Talking therapies: A four-year plan of action. Retrieved from http://www.iapt.nhs.uk/silo/files/talkingtherapies-a-four-year-plan-of-action.pdf

Department for Communities and Local Government. (2011). English indices of deprivation 2010. Retrieved from https://www.gov.uk/ government/statistics/english-indices-of-deprivation-2010

Dohrenwend, B. P., Levav, I., Shrout, P. E., Schwartz, S., Naveh, G., Link, B. G., Skodol, A. E., \& Stueve, A. (1992). Socioeconomic status and psychiatric disorders: The causation-selection issue. Science, 255(5047), 946-952. https://doi.org/10.1126/science. 1546291

Eibner, C., Sturm, R., \& Gresenz, C. R. (2004). Does relative deprivation predict the need for mental health services? The Journal of Mental Health Policy and Economics, 7, 167-175.

Fiester, A. R., Mahrer, A. R., Giambra, L. M., \& Ormiston, D. W. (1974). Shaping a clinic population: The dropout problem reconsidered. Community Mental Health Journal, 10(2), 173-179. https://doi.org/10.1007/bf01410896

Finegan, M., Firth, N., \& Delgadillo, J. (2020). Adverse impact of neighbourhood socioeconomic deprivation on psychological treatment outcomes: The role of area-level income and crime. Psychotherapy Research, 30(4), 546-554. https://doi.org/10.1080/10503 307.2019.1649500

Finegan, M., Firth, N., Wojnarowski, C., \& Delgadillo, J. (2018). Associations between socioeconomic status and psychological therapy outcomes: A systematic review and meta-analysis. Depression and Anxiety, 35(6), 560-573. https://doi.org/10.1002/da.22765
Firth, N., Allery, K., O'Cathain, A., Barkham, M., \& Delgadillo, J. (2020). Associations between socioeconomic deprivation and psychological intervention dropout: a systematic review. PROSPERO: International prospective register of systematic reviews. https://www.crd.york.ac.uk/prospero/display_record.php?ID= CRD42020187034

Firth, N., Delgadillo, J., Kellett, S., \& Lucock, M. (2019). The influence of socio-demographic similarity and difference on adequate attendance of group psychoeducational cognitive behavioural therapy. Psychotherapy Research, 30(3), 362-374. https://doi. org/10.1080/10503307.2019.1589652

Fryers, T., Melzer, D., \& Jenkins, R. (2003). Social inequalities and the common mental disorders: A systematic review of the evidence. Social Psychiatry and Psychiatric Epidemiology, 38(5), 229-237. https://doi.org/10.1007/s00127-003-0627-2

Garfield, S. L. (1989). Giving up on child psychotherapy: Who drops out? Comment on Weisz, Weiss, and Langmeyer. Journal of Consulting and Clinical Psychology, 57(1), 168-169. https://doi.org/ 10.1037/0022-006x.57.1.168

Garfield, S. L. (1994). Research on client variables in psychotherapy. In A. E. Bergin \& S. L. Garfield (Eds.), Handbook of psychotherapy and behavior change (4th ed.). Wiley.

Gavaghan, D. J., Moore, R. A., \& McQuay, H. J. (2000). An evaluation of homogeneity tests in meta-analyses in pain using simulations of individual patient data. Pain, 85(3), 415-424. https:// doi.org/10.1016/s0304-3959(99)00302-4

Goldberg, D. P., \& Huxley, P. (1992). Common mental disorders: A bio-social model. Tavistock/Routledge.

Grant, K., McMeekin, E., Jamieson, R., Fairfull, A., Miller, C., \& White, J. (2012). Individual therapy attrition rates in a lowintensity service: A comparison of cognitive behavioural and person-centred therapies and the impact of deprivation. Behavioural and Cognitive Psychotherapy, 40(2), 245-249. https:// doi.org/10.1017/s135246581100047

Gusenbauer, M., \& Haddaway, N. R. (2020). Which academic search systems are suitable for systematic reviews or meta-analyses? Evaluating retrieval qualities of Google Scholar, PubMed, and 26 other resources. Research Synthesis Methods, 11(2), 181217. https://doi.org/10.1002/jrsm. 1378

Hart, J. T. (1971). The inverse care law. The Lancet, 297(7696), 405-412. https://doi.org/10.1016/s0140-6736(71)92410-x

Higgins, J. P. T., Thomas, J., Chandler, J., Cumpston, M., Li, T., Page, M., \& Welch, V. (2019). Cochrane handbook for systematic reviews of interventions. Version 6 . Wiley.

Higgins, J. P. T., Thompson, S. G., Deeks, J. J., \& Altman, D. G. (2003). Measuring inconsistency in meta-analyses. British Medical Journal, 327(7414), 557-560. https://doi.org/10.1136/bmj. 327.7414 .557

Holder, N., Holliday, R., Wiblin, J., LePage, J. P., \& Suris, A. (2019). Predictors of dropout from a randomized clinical trial of cognitive processing therapy for female veterans with military sexual trauma-related PTSD. Psychiatry Research, 276, 87-93. https:// doi.org/10.1016/j.psychres.2019.04.022

Johansson, R., \& Andersson, G. (2012). Internet-based psychological treatments for depression. Expert Review of Neurotherapeutics, 12(7), 861-870. https://doi.org/10.1586/ern.12.63

Kaltenthaler, E., Sutcliffe, P., Parry, G., Beverley, C., Rees, A., \& Ferrite, M. (2008). The acceptability to patients of computerized cognitive behaviour therapy for depression: A systematic review. Psychological Medicine, 38(11), 1521-1530. https://doi. org/10.1017/s0033291707002607

Karyotaki, E., Kleiboer, A., Smit, F., Turner, D. T., Pastor, A. M., Andersson, G., Berger, T., Botella, C., Breton, J. M., Carlbring, P., Christensen, H., de Graaf, E., Griffiths, K., Donker, T., Farrer, L., Huibers, M. J., Lenndin, J., Mackinnon, A., Meyer, B., ... Cuijpers, P. (2015). Predictors of treatment dropout in 
self-guided web-based interventions for depression: An "individual patient data" meta-analysis. Psychological Medicine, 45(13), 2717-2726. https://doi.org/10.1017/S0033291715000665

Kehle-Forbes, S. M., Meis, L. A., Spoont, M. R., \& Polusny, M. A. (2016). Treatment initiation and dropout from prolonged exposure and cognitive processing therapy in a VA outpatient clinic. Psychological Trauma, 8(1), 107-114. https://doi.org/ $10.1037 /$ tra0000065

Klein, E. B., Stone, W. N., Hicks, M. W., \& Pritchard, I. L. (2003). Understanding dropouts. Journal of Mental Health Counselling, 25, 89-100.

Kline, A. C., Baier, A. L., Klein, A. B., Feeny, N. C., \& Zoellner, L. A. (2020). Differentiating "types" of treatment dropout: Nonstarters in an RCT of prolonged exposure versus sertraline. Behaviour Research and Therapy. https://doi.org/10.1016/j.brat.2020.103750

Kling, J. R., Liebman, J. B., \& Katz, L. F. (2007). Experimental analysis of neighborhood effects. Econometrica, 75(1), 83-119. https:// doi.org/10.1111/j.1468-0262.2007.00733.x

Kuruvilla, A., \& Jacob, K. S. (2007). Poverty, social stress \& mental health. Indian Journal of Medical Research, 126(4), 273-278.

Landis, J. R., \& Koch, G. G. (1977). Measurement of observer agreement for categorical data. Biometrics, 33(1), 159-174. https://doi. org/10.2307/2529310

Lester, K., Resick, P. A., Young-Xu, Y., \& Artz, C. (2010). Impact of race on early treatment termination and outcomes in posttraumatic stress disorder treatment. Journal of Consulting and Clinical Psychology, 78(4), 480-489. https://doi.org/10.1037/a0019551

Miller, K. E., Micol, R. L., Davis, J. L., Cranston, C. C., \& Pruiksma, K. E. (2019). Predictors of treatment noninitiation, dDropout, and response for cognitive behavioral therapy for trauma nightmares. Psychological Trauma, 11(1), 122-126. https://doi.org/10.1037/ tra0000389

Ministry of Housing, Communities \& Local Government. (2019). English indices of deprivation 2019

Moore, C. G., Wilson-Witherspoon, P., \& Probst, J. C. (2001). Time and money: Effects of no-shows at a family practice residency clinic. Family Medicine, 33(7), 522-527.

Mossakowski, K. N. (2014). Social causation and social selection. In W. C. Cockerham, R. Dingwall, \& S. R. Quah (Eds.), The Wiley Blackwell encyclopedia of health, illlness, behavior, and society (pp. 2154-2160). Wiley.

Mott, J. M., Mondragon, S., Hundt, N. E., Beason-Smith, M., Grady, R. H., \& Teng, E. J. (2014). Characteristics of U.S. veterans who begin and complete prolonged exposure and cognitive processing therapy for PTSD. Journal of Traumatic Stress, 27(3), 265-273. https://doi.org/10.1002/jts.21927

National Institute for Health and Care Excellence. (2009). Depression in adults: Recognition and management. NICE.

National Institute for Health and Care Excellence. (2011a). Common mental health problems: Identification and pathways to care. National Collaborating Centre for Mental Health.

National Institute for Health and Care Excellence. (2011b). Generalised anxiety disorder and panic disorder in adults: Management. NICE.

NHS Digital. (2020). Psychological therapies, annual report on the use of IAPT services-England, 2019-20. Retrieved from https:// digital.nhs.uk/data-and-information/publications/statistical/psych ological-therapies-annual-reports-on-the-use-of-iapt-services/ annual-report-2019-20

Oates, L., \& Firth, N. (2020). Deprivation, access, and outcomes in health psychology treatment. Mental Health Review Journal. https://doi.org/10.1108/MHRJ-02-2020-0010

O’Donoghue, B., Roche, E., \& Lane, A. (2016). Neighbourhood level social deprivation and the risk of psychotic disorders: A systematic review. Social Psychiatry and Psychiatric Epidemiology, 51(7), 941-950. https://doi.org/10.1007/s00127-016-1233-4
Pekarik, G. (1985). The effects of employing different termination classification criteria in dropout research. Psychotherapy, 22(1), 86-91. https://doi.org/10.1037/h0088531

Potts, L. C., \& Henderson, C. (2020). Moderation by socioeconomic status of the relationship between familiarity with mental illness and stigma outcomes. SSM-Population Health. https://doi.org/10. 1016/j.ssmph.2020.100611

Poverty and Social Exclusion UK. (2016). Deprivation and poverty. Retrieved from http://www.poverty.ac.uk/definitions-poverty/ deprivation-and-poverty

Richards, D., \& Richardson, T. (2012). Computer-based psychological treatments for depression: A systematic review and meta-analysis. Clinical Psychology Review, 32(4), 329-342. https://doi.org/10. 1016/j.cpr.2012.02.004

Richardson, R., Westley, T., Gariepy, G., Austin, N., \& Nandi, A. (2015). Neighborhood socioeconomic conditions and depression: A systematic review and meta-analysis. Social Psychiatry and Psychiatric Epidemiology, 50(11), 1641-1656. https://doi.org/10. 1007/s00127-015-1092-4

Roos, J., \& Werbart, A. (2013). Therapist and relationship factors influencing dropout from individual psychotherapy: A literature review. Psychotherapy Research, 23(4), 394-418. https://doi.org/ 10.1080/10503307.2013.775528

Schindler, A., Hiller, W., \& Witthoft, M. (2013). What predicts outcome, response, and drop-out in CBT of depressive adults? A naturalistic study. Behavioural and Cognitive Psychotherapy, 41(3), 365-370. https://doi.org/10.1017/s1352465812001063

Sharf, J. (2009). Meta-analysis of psychotherapy dropout. Unpublished.

Sharf, J., Primavera, L. H., \& Diener, M. J. (2010). Dropout and therapeutic alliance: A meta-analysis of adult individual psychotherapy. Psychotherapy, 47(4), 637-645. https://doi.org/10.1037/a0021175

Swift, J. K., \& Greenberg, R. P. (2012). Premature discontinuation in adult psychotherapy: A meta-analysis. Journal of Consulting and Clinical Psychology, 80(4), 547-559. https://doi.org/10.1037/ a0028226

The National Collaborating Centre for Mental Health. (2019). The Improving Access to Psychological Therapies Manual. The National Collaborating Centre for Mental Health.

Townsend, P. (1979). Poverty in the United Kingdom. Allen Lane and Penguin Books.

Townsend, P. (1987). Deprivation. Journal of Social Policy, 16, 125146. https://doi.org/10.1017/s0047279400020341

Wakefield, S., Kellett, S., Simmonds-Buckley, M., Stockton, D., Bradbury, A., \& Delgadillo, J. (2020). Improving access to psychological therapies (IAPT) in the United Kingdom: A systematic review and meta-analysis of 10-years of practice-based evidence. British Journal of Clinical Psychology. https://doi.org/10.1111/bjc.12259

Waller, R., \& Gilbody, S. (2009). Barriers to the uptake of computerized cognitive behavioural therapy: A systematic review of the quantitative and qualitative evidence. Psychological Medicine, 39(5), 705-712. https://doi.org/10.1017/s0033291708004224

Wells, G. A., Shea, B., O'Connell, D., Peterson, J., Welch, V., Losos, M., \& Tugwell, P. The Newcastle-Ottawa scale (NOS) for assessing the quality of nonrandomised studies in meta-analyses. Retrieved from www.ohri.ca/programs/clinical_epidemiology/oxford.asp

Wierzbicki, M., \& Pekarik, G. (1993). A meta-analysis of psychotherapy dropout. Professional Psychology, 24(2), 190-195. https:// doi.org/10.1037/0735-7028.24.2.190

Zieve, G. G., Persons, J. B., \& Yu, L. A. D. (2019). The relationship between dropout and outcome in naturalistic cognitive behavior therapy. Behavior Therapy, 50(1), 189-199. https://doi.org/10. 1016/j.beth.2018.05.004

Publisher's Note Springer Nature remains neutral with regard to jurisdictional claims in published maps and institutional affiliations. 